\section{COLOQUIO DE ESTUDIANTES DE FILOSOFÍA Y RELIGIÓN DE LA FACULTAD DE CIENCIAS DE LA EDUCACIÓN Y HUMANINADES}

y los nervios naturales de los ponentes daban un aire de frescura y alegría.

El coloquio se organizó en tres ponencias: dos a cargo de los estudiantes de Filosofía y Religión, Yolanda Lipa Mamani y Francisco Villanueva Huamán, y una a cargo de un invitado de otra institución académica universitaria. Para esta ocasión nos acompañó Alexandra Alván, estudiante de posgrado de la Pontificia Universidad Católica del Perú.

La participación de un de la universidad. Fue una iniciativa lograda tanto por los estudiantes de pregrado de la facultad de educación como por el Área de docentes de Filosofía, cuyo coordinador, el profesor Roberto Tejada Rivas, apoyó y dirigió toda la organización.

El coloquio mantenía mucha expectativa en especial por los mismos estudiantes de la especialidad. La asistencia al coloquio fue promedio, en su mayoría asistieron estudiantes de diferentes ciclos y varios profesores invitados. Por otro lado, el entusiasmo

\section{LAS PONENCIAS}

La primera ponencia, titulada Ética y Politica: dos realidades cercanas y unidas estuvo a cargo de la Yolanda Lipa Mamani. Se trató de una reflexión acerca del estrecho vínculo entre la ética y política. Según la 
expositora, en la actualidad, no se reconoce esta armonía debido a la inmoralidad de algunos políticos, lo cual lleva a un conformismo de escoger un «siempre mal menor», o a una desconfianza permanente entre los ciudadanos frente a los políticos de turno. Argumentó que este criterio reduccionista entre ética y política se debía a la influencia de toda una filosofía moderna, representada en las teorías de Thomas Hobbes: el realismo político, bien expresado en su célebre frase el hombre es un lobo para hombre; Nicolás Macchiavello, quien en su obra El Príncipe (1513) remarca el deber del Estado en alejarse de las cuestiones éticas para lograr los fines deseados: el fin justifica los medios; Jean-Paul Sartre, quien en Las manos sucias (1948) presenta a la política como el lugar de la hipocresía y de la inmoralidad que de ningún modo puede estar vinculada con la ética; y Max Weber, con la disyuntiva entre «la ética de la responsabilidad» y la «ética de la convicción» que conlleva un pesimismo político. Finalmente, todas estas posturas se degradan en un moralismo ético que rechaza todo vínculo con la política.

Frente a estos paradigmas, Lipa presenta la posibilidad de una verdadera armonía entre ética y política. La expositora apoya su primer argumento en el pensamiento de McIntyre, donde indica que toda sociedad requiere de ciertos «bienes internos» que les son indispensables para la vida comunitaria y esto se logra porque la ética exige virtudes indispensables para su funcionamiento, reafirmando, por tanto, que el fin propio de la política se orienta al bien común y que no se debe malinterpretar el poder con anarquismo o despotismo. El segundo argumento se sustenta en la ética aristótelica, que descubre que la ética tiene mucho que ver con la política y el buen gobierno, tanto así que Aristóteles, en su Ética a Nicómaco, afirma que sin ética no hay política. Finalmente, concluye que la ética en la política no es 
obstáculo, sino que mantiene una relación estrecha, porque suscita una permanente tensión entre ambas, porque ella es un hilo conductor que condiciona y pone límites, sin que esto debilite la política, sino que la fortalece. Asimismo, la ética política depende de la ciudadanía y no solo de los políticos; por ello, es un imperativo de todo ciudadano devolver la moral a la política y a la vida social.

La segunda ponencia estuvo a cargo de Francisco Villanueva Huamán. El tema de su trabajo, que proviene de una frase tomada del Summa Theologiae, fue IN NECESSITATE SUNT OMNIA COMMUNIA: 'en caso de (extrema) necesidad todas las cosas (bienes) son comunes'. La ponencia se propuso buscar la relación y la aplicabilidad de esta frase en el principio ético: hay que hacer el bien y evitar el mal. Comienza con una explicación precisa sobre el principio ético, hay que hacer el bien y evitar el $m a l$, indicando que es un principio universal de todo hombre y que es obligatorio tenerlo en cuenta en la experiencia cotidiana. Asimismo, hace lo propio con la frase tomista in necessitate sunt omnia communia, precisando que esta necessitate es referido a la búsqueda de bienestar en todo individuo, como comer, trabajar, estudiar, etc. La relación entre ellos radica en que la frase tomista tiene un vínculo muy cercano a la búsqueda de un bienestar de las necesidades básicas humanas. Si no es saciado, se comete un mal, pero si busca satisfacer esta necesidad se está haciendo un bien y evitando el mal. Este es la base de toda vida social armónica.

Villanueva profundiza en el tema, además, centrándose en el derecho a la propiedad, citando el artículo 17 de los derechos humanos; ${ }^{1}$ aduciendo que toda propiedad «pertenece» al necesitado y que es necesario «reconocerle» tal

1 «Toda persona tiene derecho a la propiedad, individual y colectiva». Declaración Universal de los Derechos Humanos. 
propiedad en base al mencionado principio ético y que es evidente reconocerlo como bien. Denuncia que es un mal que algunos tengan mucho más de lo que necesitan y que otros carezcan de lo necesario para vivir decentemente; del mismo modo, es necesario, nos dice, evitar que las personas carezcan de medios y de preparación para adquirir lo necesario para subsistir. Esto lo fundamenta tanto en la Política de Aristóteles como en la Summa Theologiae de santo Tomás de Aquino, conciliando así estos dos pensamientos en vínculo con el bien común, en donde se afirmaba que esto se cumple cuando alguien satisface una necesidad, sea propia o ajena teniendo en cuenta que al bien que se refiere es al bien común, donde están involucrados además el rol de la autoridad y las leyes, que deben estar al servicio de este principio. Sentencia, finalmente, que el ser humano es un ser político con facultades que deben ser puestas al servicio de hacer el bien y evitar el mal, evitando así que al hacerlo no debe permitirse dejar al otro en estado de necesidad.

Por su parte, la ponente invitada Alexandra Alván centró su trabajo en la ética y política en la Ética a Nicómaco de Aristóteles. Alván planteó, inicialmente, cómo la ética aristotélica tiene un carácter eminentemente teleológico, es decir, se trata de una ética "por fines» marcada por un ideal de realización y perfección como fin «final» (en la acepción del vocablo griego se trataría de un fin al cual no le falta nada). El análisis de algunos puntos del texto mostró cómo el Estagirita plantea, entonces, una metafísica esencialista en la que a "cada cosa le corresponde una función", y es desde este punto de vista que se debe entender el significado de la felicidad, que no es una simple emoción, sino que consistiría en vivir según el logos, como virtud por excelencia; abriendo un camino para entender mejor la actividad de la razón. Tal perfección lleva 
al hombre a adquirir (practicar) pérdida del ideal de la «unidad» en virtudes, como hábitos en los el proyecto de la construcción de la que el hombre hace el esfuerzo de persona en la sociedad. buscar un justo medio tratando Por otro lado, otro aporte efectivamente de evitar tanto los interesante fue el valor de la razón, defectos como los excesos.

no solamente como capacidad

En ese sentido, el ideal de de intelectualidad, sino como la felicidad radica, finalmente, en «racionalidad humana», que sin la contemplación de Dios, es decir, rechazar la apertura a todas las la capacidad del hombre de vivir condiciones de la realidad del ser «como Dios». Este mismo ideal personas, se muestra como «luz» para se convierte en el trasfondo de la corroborar la búsqueda de los ideales comunidad política (polis). Por eso, de perfección. para los griegos, la polis es anterior al hombre, la comunidad política

\section{DESAFÍOS Y RETOS} no puede no buscar la construcción del «hombre bueno».

Los desafíos y los retos fueron una constante en todo este recorrido.

Definitivamente hay una conclusión importante acerca de esto: los griegos mostraron cómo el ideal ético no puede estar separado de la vida política. Esta idea es un reto para los peruanos, según la ponente, ya que la dicotomía hodierna de estos dos elementos ha generado no solamente las consecuencias nefastas de un sistema político corrupto, sino sobre todo la

Experimentar un nuevo desafío por parte de los estudiantes, en este caso, su participación como ponentes, es un trabajo que evidenció otro aspecto de su labor académica que deben profundizar progresivamente. Esta experiencia fortalece el protagonismo que deben asumir en la vida universitaria: la transición de oyente a expositor no solamente 
de sus pares, sino de la comunidad universitaria de la que son parte, con la cual pueden dialogar y, sobre todo, aportar a los estudios de sus disciplinas.

El reto sigue siendo mayor. ¿Es posible un segundo coloquio de estudiantes de filosofía? Como docente considero que todogran logro parte siempre de mucha paciencia y de constante aprendizaje; pero lo que logra siempre un éxito es la forma como miramos los retos, los desafíos y qué vamos a aportar con todo esto. Si el esfuerzo se da unicamente para obtener reconocimiento, esto caduca inmediatamente en el olvido, pero si esto nace como un desafío ante los problemas actuales en la educación, en el pensamiento, en la política, en la sociedad, en la postura cómo nos enfrentemos a la realidad, dejará una base para los miembros de la comunidad universitaria. Al final, siempre es cuestión de "opción", si estamos realmente dispuestos a ser protagonistas o ser eternamente espectadores.
Finalmente, el coloquio está pensando para los estudiantes, así que, en última instancia depende de ellos, de las ganas, del esfuerzo y también, del apoyo que reciban. Esperemos que sea la primera de muchas iniciativas estudiantiles que nos llenen de alegría y orgullo.

JANINA NAVARRO LINARES ÁREA DE FILOSOFÍA Y RELIGIÓN UCSS 